\title{
Creating a Vision of Creativity: The First 25 Years
}

\author{
Robert J. Sternberg \\ Yale University
}

\begin{abstract}
This article describes three stages of my attempts to understand, measure, and develop creative thinking. The first stage explored creative intelligence. The second investigated a theory of creativity, the investment theory. The third proposed a theory of creative leadership. Together, these three stages comprise the development of my thought on creativity—its nature, measurement, and development.
\end{abstract}

Keywords: creativity, abilities, motivation, personality, intelligence

For roughly 25 years, I have been trying to understand creativity and its various aspects. Because this article is based on an American Psychological Association (APA) Division 10 Arnheim Award address for career achievement studying creativity, this seems like a good time to review what I think I have learned in 25 years.

My goal has been to create some kind of vision of creativity: What is it, how can it be measured, how can it be developed? Over the course of the years, my attempts to understand creativity have gone roughly through three stages. The stages have not been wholly sequential. Sometimes I would proceed to a next stage, only later to go back to an earlier one. My goal always has been to broaden and deepen my, and, I hope, others' understanding of creativity.

What has changed over the years are not the "answers." I have not found anything earlier that I later retracted or ceased to believe. Rather, what have changed are the questions. As time has gone on, the questions that have seemed important to ask have changed as my research interests have developed.

\section{Stage 1: Creative Intelligence \\ Early Studies of Intelligence}

My earliest work was on intelligence (e.g., Sternberg, 1977, 1979). I was trying to understand the mental representations and processes involved in solving problems on intelligence tests. But after some number of years, I came to the conclusion that this approach was narrow, because the kinds of items used on these tests covered only a narrow range. My original "componential subtheory" of intelligence (Sternberg, 1980) came to seem too narrow. Instead of trying to understand intelligence only in terms

Robert J. Sternberg, Yale University, New Haven, Connecticut.

Preparation of this article was supported by a government grant under the Javits Act Program (Grant No. R206R000001) as administered by the U.S. Institute of Educational Sciences, U.S. Department of Education. Such support does not imply acceptance or endorsement of the ideas presented in this article.

Correspondence concerning this article should be addressed to Robert J. Sternberg who is now at the Office of the Dean of Arts and Sciences, 3rd floor, Ballou Hall, Tufts University, Medford, Massachusetts 02155. Email: robert.sternberg@tufts.edu of the components of analytical intelligence, I tried to understand as well other kinds of intelligence, in particular, creative and practical thinking. I proposed what I referred to as a "triarchic" theory of intelligence (Sternberg, 1984, 1985). One of the three kinds of intelligence that I concerned myself with, the topic of discussion here, is creative intelligence. I then expanded my thinking to a theory of "successful" intelligence, which emphasized the importance not only of one's pattern of analytical, creative, and practical intelligence, but also of capitalizing on strengths and compensating for or correcting weaknesses (Sternberg, 1997a, 1999a).

\section{The Move to Studying Creative Intelligence}

Intelligence tests contain a range of problems, some of them more novel than others. In some of our componential work, we have shown that when one goes beyond the range of unconventionality of the conventional tests of intelligence, one starts to tap sources of individual differences measured little or not at all by the tests (Sternberg, 1985). According to the theory of successful intelligence, (creative) intelligence is particularly well measured by problems assessing how well an individual can cope with relative novelty. Thus, it is important to include in a battery of tests problems that are relatively novel in nature.

In work with convergent problems, we presented 80 individuals with novel kinds of reasoning problems that had a single best answer (Sternberg, 1982; Tetewsky \& Sternberg, 1986). For example, they might be told that some objects are green and others blue; but still other objects might be grue, meaning green until the year 2000 and blue thereafter, or bleen, meaning blue until the year 2000 and green thereafter. Or they might be told of four kinds of people on the planet Kyron, blens, who are born young and die young; kwefs, who are born old and die old; balts, who are born young and die old; and prosses, who are born old and die young. Their task was to predict future states from past states, given incomplete information. In another set of studies, 60 people were given more conventional kinds of inductive reasoning problems, such as analogies, series completions, and classifications, but were told to solve them. The problems had premises preceding them that were either conventional (dancers wear shoes) or novel (dancers eat shoes). The participants had to solve the problems as though the counterfactuals were true (Sternberg \& Gastel, 1989a, 1989b). 
In these studies, we found that correlations with conventional kinds of tests depended on how novel or nonentrenched the conventional tests were. The more novel the items, the higher were the correlations of our tests with scores on successively more novel conventional tests. Thus, the components isolated for relatively novel items would tend to correlate more highly with more unusual tests of fluid abilities (e.g., that of Cattell \& Cattell, 1973) than with tests of crystallized abilities. We also found that when response times on the relatively novel problems were componentially analyzed, some components better measured the creative aspect of intelligence than did others. For example, in the "gruebleen" task mentioned above, the information-processing component requiring people to switch from conventional green-blue thinking to grue-bleen thinking and then back to green-blue thinking again was a particularly good measure of the ability to cope with novelty.

\section{The Rainbow Project}

More recently, we have sought to measure creative intelligence in the context of a test designed to supplement the SAT. This test emanated from the so-called Rainbow Project (Henry, Sternberg, \& Grigorenko, 2004; Sternberg \& The Rainbow Project Collaborators, 2005; Sternberg, The Rainbow Project Collaborators, \& University of Michigan Business School Project Collaborators, 2004), an attempt to explore how to supplement the SAT in college admissions with creative and practical tests in addition to the more analytical SAT. This work thus represents a recent return to Stage 1 -an attempt to measure creative intelligence in the context of our most recent understandings.

\section{The Participants}

A battery of tests was administered in the spring and summer of 2001 to eight 4-year colleges and five community colleges. The participants were 793 students predominantly in their first year of college.

\section{The Tests}

The Sternberg Triarchic Abilities Test (STAT; Sternberg, 1993) was a means of capturing analytical, practical, and creative skills using multiple-choice questions (Sternberg \& Clinkenbeard, 1995; Sternberg, Ferrari, Clinkenbeard, \& Grigorenko, 1996). Level H of the test (Sternberg, 1993) was designed to measure cognitive skills among secondary school and college students, and was used in this study. Each multiple-choice item in the STAT had four different response options, from which the correct response could be selected. There were three analytical, three creative, and three practical subtests. The creative multiple-choice STAT subtests were:

Creative-Verbal: Novel analogies. Students are presented with verbal analogies preceded by counterfactual premises (e.g., money falls off trees). They have to solve the analogies as though the counterfactual premises were true.
Creative-Quantitative: Novel number operations. Students are presented with rules for novel number operations, for example, "flix," which involves numerical manipulations that differ as a function of whether the first of two operands is greater than, equal to, or less than the second. Participants have to use the novel number operations to solve presented math problems.

Creative-Figural: In each item, participants are first presented with a figural series that involves one or more transformations; they then have to apply the rule of the series to a new figure with a different appearance, and complete the new series.

Ability scores were computed by combining the responses to the subscales, using item response theory to create three final scales representing analytical, creative, and practical skills $\left(\mathrm{STAT}_{\text {Analytical }}, \mathrm{STAT}_{\text {Creative, }}\right.$, and $\left.\mathrm{STAT}_{\text {Practical }}\right)$. The Cronbach alpha estimates of reliability were satisfactory but not high (.67, .72 , and .56 for the analytical, creative, and practical subtests, respectively), in part because within each subtest, the content domains (verbal, quantitative, and figural) are very different from each other.

Creative performance tests had a different character. A series of tasks was created that required open-ended, creative responses. For each of the tasks, participants were given a choice of topic or stimuli. Although these different topics or stimuli varied in terms of their difficulty for inventing creative stories and captions, these differences are accounted for in the derivation of Item Response Therapy (IRT) ability estimates using the Many-Facets Rasch model (Linacre, 1989) of the FACETS computer program (Linacre, 1998).

Cartoons. Participants were given five cartoons purchased from the archives of the New Yorker, but with the captions removed. The participants' task was to choose three cartoons and to provide a caption for each cartoon. Two trained judges rated all the cartoons for cleverness, humor, originality, and task appropriateness on 5-point scales. A combined creativity score was formed by deriving ability estimates based on a composite of all ratings except for task appropriateness, which theoretically is not a measure of creativity per se. The IRT reliability for the composite was very good.

Written stories. Participants were asked to write two stories, spending about 15 minutes on each, choosing from the following titles: "A Fifth Chance," "2983," "Beyond the Edge," "The Octopus's Sneakers," "It's Moving Backwards," and "Not Enough Time" (Lubart \& Sternberg, 1995; Sternberg \& Lubart, 1995). A team of six judges was trained to rate the stories. Each judge rated the stories for originality, complexity, emotional evocativeness, and descriptiveness on 5-point scales. Because the reliability based on the total score for each story was satisfactory, for purposes of efficiency, $64.7 \%$ of the stories were rated by one of the six judges. 
The IRT reliability indices for the composite person ability estimates for the written stories were very good.

Oral stories. Participants were presented with five sheets of paper, each containing a set of 11 to 13 images linked by a common theme (e.g., keys, money, travel, animals playing musical instruments, and humans playing musical instruments). After choosing one of the pages, the participant was given 15 minutes to formulate a short story and dictate it into a cassette recorder. The dictation period for each story was not to be more than 5 minutes long. The process was then repeated with another sheet of images so that each participant dictated a total of two oral stories. Six judges were trained to rate the stories. As with the written stories, each judge rated the stories for originality, complexity, emotional evocativeness, and descriptiveness on 5-point scales. Because interrater reliability based on the total score for each story was satisfactory, for purposes of efficiency, $48.4 \%$ of the stories were rated by one of the six judges. The IRT reliability indices for the composite person ability estimates for the oral stories were very good.

School performance was measured using cumulative grade point average as obtained from school transcripts.

All materials were administered either in paper-and-pencil format $(N=325)$ or on the computer via the World Wide Web $(N=$ 468). Participants were either tested individually or in small groups. During the oral stories section, participants who were tested in the group situation either wore headphones or were directed into a separate room so as not to disturb the other participants during the oral dictation of the stories.

There were two discrete sessions, conducted one directly after the other, for each participant. The order of test administration was the same for all participants. No strict time limits were set for completing the tests, although the instructors were given rough guidelines of about 70 minutes per session. The time taken to complete the battery of tests ranged from 2 to 4 hours.

As a result of the lengthy nature of the complete battery of assessments, participants were administered parts of the battery using an intentional incomplete overlapping design, as described in McArdle and Hamagami (1992; also McArdle, 1994). The participants were randomly assigned to the test sections they were to complete. All missing data in the sample were managed using the full-information maximum likelihood (FIML) technique (see McArdle, 1994; Wothke, 2000).

\section{The Validity Data}

An exploratory factor analysis with Varimax rotation was conducted to explore the factor structure underlying the measures in this study. Three factors were extracted with eigenvalues greater than 1 , and these accounted for $59.2 \%$ of the variation between the measures.

The results suggest that, consistent with the analyses reported above, evidence for a unidimensional latent creativity factor is mixed. It would seem that, in this sample, the common methodological factor might have overwhelmed the unique creative, practical, and analytic contribution offered by the different STAT subtests. However, as will be demonstrated below, in terms of incremental validity, the three STAT variables each contributed uniquely to the prediction of college grade point average (GPA).

In order to test the incremental validity provided by our measures, a series of hierarchical regressions was conducted that included the items analyzed above in the analytic, creative, and practical abilities. We used the Mplus computer program to analyze the hierarchical multiple regressions, and for specification purposes for the structural equation models we constrained the six lowest correlations in the correlation matrix to zero (not doing so would have left the model with negative degrees of freedom). The creativity measures in these hierarchical regressions are separated from their latent variable because, as noted earlier, these items did not include enough common variance to justify using a latent variable in further analysis.

The hierarchical regressions show that measures representing each of the triarchic measures of intelligence significantly predicted success in college as represented by college grade-point average. In the first stage we began with the practical intelligence measures. Both measures of practical intelligence significantly contributed to predicting college GPA, and together predicted $7.4 \%$ of the variance in GPA. In the second stage of the regression we added the creativity measures. Both practical intelligence measures remain statistically significant, and the oral stories and creative STAT contribute significantly to the model. Together, the added creativity items double the amount of variance contributed by the practical measures $\left(R^{2}=15.3 \%\right)$. Finally, in the last step we added the analytic STAT measure, which also contributes significantly to the regression model and adds $1 \%$ to the GPA variance predicted by all measures $(16.3 \%)$. By this last stage, at least one measure from each of the aspects of intelligence was represented as significant contributors to the model: the practical performance latent variable (including all three tacit-knowledge inventories), the oral stories, and the creative and analytic STAT measures.

\section{Group-Differences Data}

Although one important goal of the present study was to predict success in college, another important goal involved developing measures that might reduce gender, racial, and ethnic group differences in the mean levels for the predictor variables. There are a number of ways one can test for group differences in these measures, each involving a test of the size of the effect of race. We chose two different measures of effect size: omega square $\left(\omega^{2}\right)$, and Cohen's $d$.

To test our success in minimizing group differences with the new measures, we first considered the omega square coefficients. This procedure involves conducting a series of one-way analyses of variance (ANOVA) considering differences in mean performance levels among different groups. The omega-squared coefficient indicates the amount of variance in the variables that is accounted for by the group differences.

We first tested for differences between the six ethnic and racial groups reported, including White, Asian, Pacific Islander, Latino, Black, and Native American. Although most of the measures indicated a statistically significant $F$ statistic, consider the omegasquared statistic, which is not vulnerable to the size of the sample. All of the individual measures had $\omega^{2} \leq .03$, suggesting that, at most, $3 \%$ of the variance in each individual measure could be accounted for by racial and ethnic difference. For the practical latent variable, the number becomes somewhat increased, $\omega^{2}=$ .05 .

When considering the differences between men and women, most of the tests resulted in an omega-squared statistic of zero 
(including some with statistically significant $F$ statistics). However, for one of the practical performance measures, the Common Sense measure, $5 \%$ of the variance could be explained by the participant's gender. As will be shown in the Cohen's $d$ statistics, this is because women outperformed men on this measure.

The test of effect sizes using the Cohen's $d$ statistic allows one to consider more specifically a standardized representation of specific group differences. For the test of ethnic group differences, each entry represented how far away from the mean for Whites each group performs in terms of standard deviations. For the test of gender differences, the entries represented how far away from the mean for men that the women perform in terms of standard deviations.

These results illuminate findings that go beyond the omegasquared statistic. First, the Black and Latino students seem to be negatively affected by the group differences. However, when compared to reported group differences on other predictors of college success, like the SAT and ACT, these scores show a marked improvement. For example, a study conducted in 1998 showed that Blacks and Latinos consistently score from between half to a full standard deviation away on standardized tests: $-.83,-.92$, and -.98 for Blacks on the SAT-Verbal, SAT-Math, and ACTComposite, respectively; and $-.63,-.61$, and -.60 for Latinos on the SAT-Verbal, SAT-Math, and ACT-Composite, respectively (Camara \& Schmidt, 1999).

Second, to the extent that gender differences exist in our measures, they are most visible among the practical performance measures where women tend to outperform the men. For the Common Sense measure, this results in scores as much as half a standard deviation above men. Nevertheless, on measures like the STAT-Analytic, women still perform below men, but this is only by about one fifth a standard deviation.

Overall, although the group differences are not perfectly reduced, these findings suggest that measures may be designed to reduce ethnic and racial group differences on standardized tests, particularly for historically disadvantaged groups like Black and Latino students. These findings have important implications for reducing adverse impact wherever these tests might be used, such as college admissions.

\section{Instructional Studies}

Another way of exploring creativity is to look at how one can develop it and at the same time enhance school achievement. In a first set of studies, we explored the question of whether conventional education in school systematically discriminates against children with creative and practical strengths (Sternberg \& Clinkenbeard, 1995; Sternberg, Ferrari, Clinkenbeard, \& Grigorenko, 1996; Sternberg, Grigorenko, Ferrari, \& Clinkenbeard, 1999). Motivating this work was the belief that the systems in most schools strongly tend to favor children with strengths in memory and analytical abilities. However, schools can be unbalanced in other directions as well. One school Elena Grigorenko and I visited in Russia in 2000 placed a heavy emphasis upon the development of creative abilities-much more so than on the development of analytical and practical abilities.

We used the Sternberg Triarchic Abilities Test, as described above, in some of our instructional work. The test was administered to 326 children around the United States and in some other countries who were identified by their schools as gifted by any standard whatsoever. Children were selected for a summer program in (college-level) psychology if they fell into one of five ability groupings: high analytical, high creative, high practical, high balanced (high in all three abilities), or low balanced (low in all three abilities). Students who came to Yale were then divided into four instructional groups. Students in all four instructional groups used the same introductory-psychology textbook (a preliminary version of Sternberg [1995a]) and listened to the same psychology lectures. What differed among them was the type of afternoon discussion section to which they were assigned. They were assigned to an instructional condition that emphasized either memory, analytical, creative, or practical instruction. For example, in the memory condition, they might be asked to describe the main tenets of a major theory of depression. In the analytical condition, they might be asked to compare and contrast two theories of depression. In the creative condition, they might be asked to formulate their own theory of depression. In the practical condition, they might be asked how they could use what they had learned about depression to help a friend who was depressed.

Students in all four instructional conditions were evaluated in terms of their performance on homework, a midterm exam, a final exam, and an independent project. Each type of work was evaluated for memory, analytical, creative, and practical quality. Thus, all students were evaluated in exactly the same way.

Our results suggested the utility of the theory of successful intelligence. This utility showed itself in several ways.

First, we observed when the students arrived at Yale that the students in the high creative and high practical groups were much more diverse in terms of racial, ethnic, socioeconomic, and educational backgrounds than were the students in the high-analytical group, suggesting that correlations of measured intelligence with status variables such as these may be reduced by using a broader conception of intelligence. Thus, the kinds of students identified as strong differed in terms of populations from which they were drawn in comparison with students identified as strong solely by analytical measures. More importantly, just by expanding the range of abilities measured, we discovered intellectual strengths that might not have been apparent through a conventional test.

Second, we found that all three ability tests-analytical, creative, and practical—significantly predicted course performance. When multiple-regression analysis was used, at least two of these ability measures contributed significantly to the prediction of each of the measures of achievement. Perhaps as a reflection of the difficulty of deemphasizing the analytical way of teaching, one of the significant predictors was always the analytical score. (However, in a replication of our study with low-income AfricanAmerican students from New York, Deborah Coates of the City University of New York found a different pattern of results. Her data indicated that the practical tests were better predictors of course performance than were the analytical measures, suggesting that what ability test predicts what criterion depends on population as well as mode of teaching.)

Third and most importantly, there was an aptitude-treatment interaction whereby students who were placed in instructional conditions that better matched their pattern of abilities outperformed students who were mismatched. In other words, when students are taught in a way that fits how they think, they do better in school. Children with creative and practical abilities, who are 
almost never taught or assessed in a way that matches their pattern of abilities, may be at a disadvantage in course after course, year after year.

A follow-up study (Sternberg, Torff, \& Grigorenko, 1998a, 1998b) examined learning of social studies and science by thirdgraders and eighth-graders. The 225 third-graders were students in a very low-income neighborhood in Raleigh, North Carolina. The 142 eighth-graders were students who were largely middle to upper-middle class studying in Baltimore, Maryland, and Fresno, California. In this study, students were assigned to one of three instructional conditions. In the first condition, they were taught the course that basically they would have learned had there been no intervention. The emphasis in the course was on memory. In a second condition, students were taught in a way that emphasized critical (analytical) thinking. In the third condition, they were taught in a way that emphasized analytical, creative, and practical thinking. All students' performance was assessed for memory learning (through multiple-choice assessments) as well as for analytical, creative, and practical learning (through performance assessments).

As expected, students in the successful-intelligence (analytical, creative, practical) condition outperformed the other students in terms of the performance assessments. One could argue that this result merely reflected the way they were taught. Nevertheless, the result suggested that teaching for these kinds of thinking succeeded. More important, however, was the result that children in the successful-intelligence condition outperformed the other children even on the multiple-choice memory tests. In other words, to the extent that one's goal is just to maximize children's memory for information, teaching for successful intelligence is still superior. It enables children to capitalize on their strengths and to correct or to compensate for their weaknesses, and it allows children to encode material in a variety of interesting ways.

Grigorenko and her colleagues extended these results to reading curricula at the middle-school and the high-school level (Grigorenko, Jarvin, \& Sternberg, 2002). In a study of 871 middle school students and 432 high school students, researchers taught reading either triarchically or through the regular curriculum. At the middle school level, reading was taught explicitly. At the high school level, reading was infused into instruction in mathematics, physical sciences, social sciences, English, history, foreign languages, and the arts. In all settings, students who were taught triarchially substantially outperformed students who were taught in standard ways.

Thus, the results of three sets of studies suggest that teaching for creativity (as well as other kinds of thinking) can improve school achievement. Creative students do not profit as much as some other students from standard kinds of teaching. Moreover, the results suggest that the theory can make a difference not only in laboratory tests, but in school classrooms and even the everyday life of adults as well.

\section{Stage 2: The Investment Theory of Creativity}

\section{Terms of the Theory}

With Todd Lubart, I proposed an "investment" theory of creativity (Sternberg \& Lubart, 1991, 1995). According to this theory, creative people are ones who are willing and able to "buy low and sell high" in the realm of ideas (see also Rubenson \& Runco, 1992, for use of concepts from economic theory). Buying low means pursuing ideas that are unknown or out of favor but that have growth potential. Often, when these ideas are first presented, they encounter resistance. The creative individual persists in the face of this resistance, and eventually sells high, moving on to the next new, or unpopular idea.

Research within the investment framework has yielded support for this model (Lubart \& Sternberg, 1995). This research, which later served in part as the basis for the Rainbow Project work on creativity discussed earlier, has used tasks such as (a) writing short-stories using unusual titles (e.g., "The Octopus' Sneakers"), (b) drawing pictures with unusual themes (e.g., the earth from an insect's point of view), (c) devising creative advertisements for boring products (e.g., cufflinks), and (d) solving unusual scientific problems (e.g., how we could tell if someone had been on the moon within the past month?). This research showed creative performance to be moderately domain-specific and to be predicted by a combination of certain resources, as described below.

According to the investment theory, creativity requires a confluence of six distinct but interrelated resources: intellectual abilities, knowledge, styles of thinking, personality, motivation, and environment. Although levels of these resources are sources of individual differences, often the decision to use the resources is the more important source of individual differences.

\section{Facets of Creativity}

\section{Intellectual Abilities}

Three intellectual skills are particularly important (Sternberg, 1985): (a) the synthetic ability to see problems in new ways and to escape the bounds of conventional thinking; (b) the analytic ability to recognize which of one's ideas are worth pursuing and which are not; and (c) the practical-contextual ability to know how to persuade others of - to sell other people on-the value of one's ideas. The confluence of these three abilities is also important. Analytic ability used in the absence of the other two abilities results in powerful critical, but not creative thinking. Synthetic ability in the absence of the other two abilities results in new ideas that are not subjected to the scrutiny required to make them work. And practical-contextual ability in the absence of the other two may result in the transmittal of ideas not because the ideas are good, but rather because the ideas have been well and powerfully presented. To be creative, one must first decide to generate new ideas, analyze these ideas, and sell the ideas to others. The studies described above address the issue of intelligence and creativity.

\section{Knowledge}

Concerning knowledge, on the one hand, one needs to know enough about a field to move it forward. One can't move beyond where a field is if one doesn't know where it is. On the other hand, knowledge about a field can result in a closed and entrenched perspective, resulting in a person's not moving beyond the way in which he or she has seen problems in the past (Frensch \& Sternberg, 1989). Thus, one needs to decide to use one's past knowledge, but also decide not to let the knowledge become a hindrance rather than a help. 


\section{Thinking Styles}

With regard to thinking styles, a legislative style is particularly important for creativity (Sternberg, 1988, 1997b; Zhang \& Sternberg, 2005, 2006), that is, a preference for thinking and a decision to think in new ways. This preference needs to be distinguished from the ability to think creatively: Someone may like to think along new lines, but not think well, or vice versa. It also helps, to become a major creative thinker, if one is able to think globally as well as locally, distinguishing the forest from the trees and thereby recognizing which questions are important and which ones are not.

\section{Personality}

Numerous research investigations (summarized in Lubart, 1994, and Sternberg \& Lubart, 1991, 1995) have supported the importance of certain personality attributes for creative functioning. These attributes include, but are not limited to, willingness to overcome obstacles, willingness to take sensible risks, willingness to tolerate ambiguity, and self-efficacy. In particular, buying low and selling high typically means defying the crowd, so that one has to be willing to stand up to conventions if one wants to think and act in creative ways. Note that none of these attributes are fixed. One can decide to overcome obstacles, take sensible risks, and so forth.

\section{Motivation}

Intrinsic, task-focused motivation is also essential to creativity. The research of Amabile (1983) and others has shown the importance of such motivation for creative work, and has suggested that people rarely do truly creative work in an area unless they really love what they are doing and focus on the work rather than the potential rewards. Motivation is not something inherent in a person: One decides to be motivated by one thing or another.

\section{Environment}

Finally, one needs an environment that is supportive and rewarding of creative ideas. One could have all of the internal resources needed in order to think creatively, but without some environmental support (such as a forum for proposing those ideas), the creativity that a person has within him or her might never be displayed.

\section{Confluence}

Concerning the confluence of components, creativity is hypothesized to involve more than a simple sum of a person's level on each component. First, there may be thresholds for some components (e.g., knowledge) below which creativity is not possible regardless of the levels on other components. Second, partial compensation may occur in which strength on one component (e.g., motivation) counteracts a weakness on another component (e.g., environment). Third, interactions may also occur between components, such as intelligence and motivation, in which high levels on both components could multiplicatively enhance creativity.

Creative ideas are both novel and valuable, but they are often rejected because the creative innovator stands up to vested inter- ests and defies the crowd. The crowd does not maliciously or willfully reject creative notions. Rather, it does not realize, and often does not want to realize, that the proposed idea represents a valid and advanced way of thinking. Society generally perceives opposition to the status quo as annoying, offensive, and as reason enough to ignore innovative ideas.

Evidence abounds that creative ideas are often rejected (Sternberg \& Lubart, 1995). Initial reviews of major works of literature and art are often negative. Toni Morrison's Tar Baby received negative reviews when it was first published, as did Sylvia Plath's The Bell Jar. The first exhibition in Munich of the work of Norwegian painter Edvard Munch opened and closed the same day because of the strong negative response from the critics. Some of the greatest scientific papers have been rejected not just by one, but by several journals before being published. For example, John Garcia, a distinguished biopsychologist, was immediately denounced when he first proposed that a form of learning called classical conditioning could be produced in a single trial of learning (Garcia \& Koelling, 1966).

From the investment view, then, the creative person buys low by presenting a unique idea and then attempting to convince other people of its value. After convincing others that the idea is valuable, which increases the perceived value of the investment, the creative person sells high by leaving the idea to others and moving on to another idea. People typically want others to love their ideas, but immediate universal applause for an idea usually indicates that it is not particularly creative.

Creativity is as much a decision about and an attitude toward life as it is a matter of ability. Creativity is often obvious in young children, but it may be harder to find in older children and adults because their creative potential has been suppressed by a society that encourages intellectual conformity. Yet, anyone can decide for creativity.

In work with divergent reasoning problems having no one best answer, we asked 63 people to create various kinds of products (Lubart \& Sternberg, 1995; Sternberg \& Lubart, 1991, 1995, 1996) where an infinite variety of responses were possible. Individuals were asked to create products in the realms of writing, art, advertising, and science. In writing, they would be asked to write very short stories for which we would give them a choice of titles, such as "Beyond the Edge" or "The Octopus's Sneakers." In art, the participants were asked to produce art compositions with titles such as "The Beginning of Time" or "Earth from an Insect's Point of View." In advertising, they were asked to produce advertisements for products such as a brand of bow tie or a brand of doorknob. In science, they were asked to solve problems such as one asking them how people might detect extraterrestrial aliens among us who are seeking to escape detection. Participants created two products in each domain.

We found, first, that creativity comprises the components proposed by our investment model of creativity: intelligence, knowledge, thinking styles, personality, and motivation. Second, they found that creativity is relatively although not wholly domainspecific. Correlations of ratings of the creative quality of the products across domains were lower than correlations of ratings and generally were at about the .4 level. Thus, there was some degree of relation across domains, at the same time that there was plenty of room for someone to be strong in one or more domains but not in others. Third, we found a range of correlations of 
measures of creative performance with conventional tests of abilities. As was the case for the correlations obtained with convergent problems, correlations were higher to the extent that problems on the conventional tests were nonentrenched. For example, correlations were higher with fluid than with crystallized ability tests, and correlations were higher, the more novel the fluid test was. These results that tests of creative intelligence have some overlap with conventional tests (e.g., in requiring verbal skills or the ability to analyze one's own ideas-Sternberg \& Lubart, 1995) but also tap skills beyond those measured even by relatively novel kinds of items on the conventional tests of intelligence.

The work on creativity revealed a number of sources of individual and developmental differences.

1. To what extent was the thinking of the individual novel or nonentrenched?

2. What was the quality of the individual's thinking?

3. To what extent did the thinking of the individual meet the demands of the task?

\section{Stage 3: Creative Leadership \\ Types of Creative Leadership}

In my most recent work, I have become interested in the question of what constitutes creative leadership (Sternberg, 1999b; Sternberg, Kaufman, \& Pretz, 2001, 2002, 2003, 2004; Sternberg \& Vroom, 2002). I believe that creative leadership can be of different types (Sternberg, 1999b; Sternberg, Kaufman, \& Pretz, 2003). Some of these types accept current ways of doing things, others do not; and still another attempts to integrate different current practices. Which types are more acceptable depends upon the interaction of the leader with the situation. The types of creative leadership are

- Replication. This type of leadership is an attempt to show that a field or organization is in the right place at the right time. The leader therefore attempts to maintain it in that place. The leader keeps the organization where it is rather than moving it. The view of the leader is that the organization is where it needs to be. The leader's role is to keep it there.

- Redefinition. This type of leadership is an attempt to show that a field or organization is in the right place, but not for the reason(s) that others, including previous leaders, think it is. The current status of the organization thus is seen from a different point of view. Redefiners often end up taking credit for ideas of others because they find a better reason to implement the others' ideas, or say they do.

- Forward incrementation. This type of leadership is an attempt to lead a field or an organization forward in the direction it already is going. The leader specializes to forward motion. Most leadership is probably forward incrementation. In such leadership, one takes on the helm with the idea of advancing the leadership program of whomever one has succeeded. The promise is of progress through continuity. Creativity through forward incrementation is probably the kind that is most easily recognized and appreciated as creativity. Because it extends existing notions, it is seen as creative. Because it does not threaten the assumptions of such notions, it is not rejected as useless or even harmful.
- Advance forward incrementation. This type of leadership is an attempt to move an organization forward in the direction it is already going, but by moving beyond where others are ready for it to go. The leader moves followers in an accelerated way beyond the expected rate of forward progression. Advance forward incrementations usually are not successful at the time they are attempted, because followers in fields and organizations are not ready to go where the leader wants to lead. Or significant portions of them may not wish to go to that point, in which case they form an organized and sometimes successful source of resistance.

- Redirection. This type of leadership is an attempt to redirect an organization, field, or product line from where it is headed toward a different direction. Redirective leaders need to match to environmental circumstances to succeed (Sternberg \& Vroom, 2002). If they do not have the luck to have matching environmental circumstances, their best intentions may go awry.

- Reconstruction/redirection. This type of creative leadership is an attempt to move a field or an organization or a product line back to where it once was (a reconstruction of the past) so that it may move onward from that point, but in a direction different from the one it took from that point onward.

- Reinitiation. This type of leadership is an attempt to move a field, organization, or product line to a different as yet unreached starting point and then to move from that point. The leaders takes followers from a new starting point in a direction that is different from that the field, organization, or product line previously has pursued.

- Synthesis. In this type of creative leadership, the creator integrates two ideas that previously were seen as unrelated or even as opposed. What formerly were viewed as distinct ideas now are viewed as related and capable of being unified. Integration is a key means by which progress is attained in the sciences. It represents neither an acceptance nor a rejection of existing paradigms, but rather, a merger of them.

\section{Stories of Creative Leadership}

\section{Contents of Creativity: Stories}

Leaders generate stories that appeal in various degrees to their followers. These stories, like stories of love (Sternberg, 1998), attract followers in various degrees. In unsuccessful leaders, they leave followers indifferent, or even repulsed, as in stories of hate (see Sternberg, 2003). Whether a story works or not, therefore, is a contingency dependent upon the leader, the followers, and the situation (Ayman, 2004).

Stories provide much of the content of creativity in leadership. They are the way in which a leader distinguishes him or herself and the contribution he or she plans to make. The story a leader tells is not necessarily constructive, as leaders such as Hitler and Stalin have shown. Hitler's story as a savior of the Aryan race resulted in millions of death and much suffering. People must understand their leaders' stories if they are to understand whether the leader will do good or ill.

\section{Characteristics of Stories}

Gardner's view of leadership stories. Gardner (1995) has suggested that successful leaders have a story to tell and a message to 
convey. The story tends to be more effective to the extent that it appeals to what Gardner (1991) refers to as the "unschooled mind," that is, a mind that, in terms of modern cognitive theory, is more experiential than rational in its thinking (Sloman, 1996). Stories need to address both individuals' own identities and those of the group or groups to which they belong. A story is more likely to succeed if it is central to what the leader actually does in his or her action, if the story can be unfolded over a long period of time, and if it can be stated in a time of relative calm. In times of crisis, according to Gardner, stories need to be simplified.

Stories may be inclusionary or exclusionary. Inclusionary leaders try to ensure that all of the followers for whom they are responsible somehow are made to feel inside the fold. Exclusionary leaders do not include everyone and in extreme cases, such as Hitler or Stalin, turn on segments of the population whom they are entrusted to leader.

The story must reach an audience. Gardner (1995) points out that no matter what the story, if there is no audience for it, it is dead. So a leader needs a story to which his or her audience will respond. The leader needs to take into account the experiential mode of thinking of the audience and the kinds of changes in points of view to which the audience is likely to be responsive. The leader must also have an organizational structure to implement the structure. Further, he or she needs in some way embody the story he or she has to tell. If the leader fails to do so, then that leader's leadership may come to be seen as bankrupt. For example, coverups by Richard Nixon and Bill Clinton seriously undermined their leadership because they came to be seen as leaders who held others to one standard and themselves to another. Many people recently have lost faith in certain church leaders who held their flocks to a standard of morality that they themselves flagrantly violated by abusing children or covering up such abuse. One cannot lead effectively if one asks people to do as one says, not as one does.

Gardner (2004) has further suggested that a good story overcomes resistances. Leaders must expect groups of followers to resist some of the leaders' ideas. It is the leaders' responsibility to devise ways to overcome these resistances. Good stories also involve representational redescription. Ideas can be expressed in many ways. The more different ways in which a leader's ideas can be expressed, and the more compelling these ways are, the more likely the leader is to persuade followers to come along. A good story also embodies resonance. At a given time and in a given place, certain ideas will resonate with followers, others will not. Establishing resonance can go a long way toward persuading people to listen. Finally, the story will be more effective to the extent it incorporates real-world events. Followers need to see how the leader's ideas relate to the lives the followers live from day to day.

Sternberg's characterization of stable story elements. Stories have certain stable elements (Sternberg, 1995b; Sternberg, Hojjat, $\&$ Barnes, 2001). First, they have beginnings, middles, and ends. In this way, they are like scripts (Schank \& Abelson, 1977). Sometimes, leaders start with a story that works well in the beginning and discover that the end does not work. They either change stories, or they lose the support of their followers. Indeed, stories are constantly being rewritten in order to suit the needs of the leader-follower unit. For example, the story of the war in Iraq changed multiple times in 2004 in order to accommodate emerging facts and the perceived needs of followers. Some individuals found it distressing that many people cared so little about the changes in the stories. They cared more about having a story with resonance than one that was necessarily "true" in any meaningful sense.

Stories also have plots, themes, and characters. For example, a common story now for political leaders is the warrior chieftain who will fight terrorists. The plot is the battle against terrorists. Themes give stories meaning. They help people understand why the story is important and what script it will follow. One theme is that the leader must constantly prepare his followers to combat the terrorists; another is that followers must give up some of their liberty to enable the leader to fight the terrorists in an effective way. Vladimir Putin, for example, announced in September 2004, a major reorganization of the Russian government to enable effective mobilization against terrorists. The reorganization concentrated more power in his hands. The characters in the battle are the terrorists, the victims, the warriors who oppose the terrorists, and the audience that watches what is happening,

Perceptions of leaders are filtered through stories. The reality may be quite different from the stories. For example, Stalin was responsible for the deaths of many millions of Soviet and other citizens. Yet when he died, there was a great deal of sadness among many citizens of the USSR. For many years, Stalin was idolized, despite his responsibility for so many deaths. Even today, many people still idolize Hitler. People see the leaders only through their stories, not through any objective reality. The stories may be based in part on objective reality, but the part may be fairly small.

It is important to realize that stories are social constructions. Different people and different groups may interpret the same events in different ways. Leadership is the attempt to capture the minds of the people to accept one's version of events. In presidential campaigns, such as that of 2004 between Bush and Kerry, much of the campaign is devoted to the fight for the storyline that people will accept. For example, was the war in Iraq a war against international terrorists or against a bad regime unconnected with the terrorists? The candidates took opposite positions, each trying to persuade listeners to believe their story. Of course, there is a truth underlying the battle: The regime either was or was not connected to international terrorists. For better or worse, truth plays at best a minor role in persuading people one way or another. Strong emotions, such as fear, rage, joy, and sorrow, probably play much more powerful roles.

Stories are hierarchically arranged so that people have multiple stories they can accept at a given time. The challenge of the leader is to create a story that is higher in people's hierarchies rather than lower. Moreover, the leader in a competition may try to undermine the story or stories of his or her competitors, trying to show that the story he or she proposes is the one that followers should accept. Again, truth may play a relatively small role in what stories people accept. Rather, their emotional needs are likely to be key. Effective leaders know this, and pitch their stories to resonate with people's emotions.

Stories can become self-fulfilling prophecies. For example, the governments of both the United States and Russia have a history of acting aggressively toward nations or interest groups that displease them. In Chechnya, the Russian government has acted in very harsh ways to suppress rebellions. The harshness of the actions creates resistance, which in turn creates more harshness, and so forth. The same dynamic has played out in the Israeli-Palestinian 
conflict. When people have stories, they act in ways to make them come true, and often they do.

Stories always have two principal roles. One is for the leader, the other for followers. Some of the stories are more symmetrical, others less so. For example, a democratic leader expects a great deal of participation from followers in setting and determining policies. An autocratic leader expects little or no participation. Leaders and followers clearly differ in the level of symmetry with which they are comfortable. For example, Russia has a history of less symmetry, and when more symmetry was introduced, the system as implemented under Boris Yeltsin was not particularly successful. Today, Vladimir Putin is moving back toward a more asymmetrical system.

\section{Classification of Stories}

Christopher Rate, a graduate student at Yale, and I are working to create and test a taxonomy of stories. Our main hypothesis is that leaders will succeed differentially well, depending in large part on the extent of match between the stories of the leaders and the followers. Some tentative examples of stories we are exploring are

- The carpenter-The leader who can build a new organization or society

- The CEO - The leader who can "get things done"

- The communicator-The leader who can communicate with diverse followers

- The conquerer-The leader who is going to conquer all enemies

- The conserver-The leader who will make sure things stay the wonderful way they are

- The cook-The leader who has the recipe to improve the life of his or her followers

- The deep thinker-The leader who will make sense out of what is going on

- The defender-The leader who will save all followers from harm

- The deity-The leader who presents him or herself as savior

- The diplomat-The leader who can get everyone to work together

- The doctor-The leader who can cure what is wrong with the organization

- The ethicist-The leader who pledges to clean up the place

- The lifesaver-The leader who will rescue followers from otherwise certain death

- The organizer-The leaders who can create order out of chaos

- The plumber-The leader who can fix all the leaks

- The politician-The leader who understands how "the system" works

- The replicator-The leader who is going to be like some past individual

- The scout-The leader who can lead followers to new and uncharted territory

- The ship captain-The captain of a ship navigating through turbulent times

- The turn-around specialist-The leader who can turn around a failing organization

- The warrior chieftain-The leader who will lead followers to fight, defensively or offensively, enemies, seen or unseen
In terms of the model of types of creativity described above, the kinds of leaders vary widely. Replicators and conservers pretty much leave existing paradigms as they are. Doctors change things that are wrong. Turn-around specialists make major changes in the organization they lead. They are redirectors or reinitiators.

\section{Success or Failure of Stories}

Leaders succeed to the extent that they (a) have a story that fits their followers' needs, (b) communicate that story in a compelling way, (c) implement the story in a way that suggests it is succeeding (given that there may be a difference between the perception and the reality), and (d) persuade followers, in the end, that the story accomplished what it was supposed to have accomplished. Leaders fail to the extent that they (a) have a story that fails to fit their followers' needs, (b) fail in communicating their story, (c) fail in implementing the story, (d) fail in persuading followers that they have accomplished what they promised, (e) fail to have any coherent story at all, (f) seem to move from story to story without convincing followers that there is a need to change stories, or $(\mathrm{g})$ allow a story of successful leadership to be replaced with a story of personal failings. For example, the leader may come to be viewed as in power not to lead, but to maintain power at all costs, to enrich him or herself personally, to increase his or her power to the maximum extent possible, or to harm groups not obeying him or her. In these cases, stories of leadership come to be replaced with stories of personal failings. Joseph Stalin, Adolph Hitler, and many other leaders eventually lost the mantle of leadership as a result of such personal failings.

In the 2004 U.S. presidential election, for example, John Kerry's campaign floundered over the summer. Why? First, it was not clear what his story is. Or if he had a clearly defined story, he failed adequately to convey it. Second, he did not persuade people that he would be able to implement a story, if he had one. Third, he allowed Bush to define the story to which people paid attention, namely, one of a leader who would be a defender and even as a warrior in the face of threats of terrorism. Fourth, he allowed the Bush campaign to portray him as a "flip-flopper," that is, someone who kept changing stories in the hope of finding one that worked.

Leaders need to be creative in inventing their stories, analytically intelligent in addressing the strengths and weaknesses of their stories, practically intelligent in implementing the stories and persuading followers to listen to them, and wise in generating and instantiating stories that are for the common good. They may fail if they lack creativity, intelligence, or wisdom, and especially if they foolishly succumb to the fallacies described earlier (such as egocentrism), which can divert them from a successful leadership story to a story of failed leadership.

Stories fit into a contingency-based notion of leadership. There is no one story that works for all organizations in all times or all places. Rather, success of a story fits into the situation at a given time and place. When Tolstoy speculated, in Anna Karenina, that if it had not been Napoleon, it would have been someone else fitting that particular situation, he was partially right. The situation demanded a certain kind of story. But it was not certain that anyone would come along who could tell that story in a compelling way and convince people to listen to him or her.

Creativity is in itself insufficient for successful leadership. In addition to being able to come up with good ideas, a good leader 
needs to know how to analyze and evaluate his or her ideas. Successful intelligence is instrumental in this evaluation process.

\section{Conclusions}

For 25 years or so, I have been trying to understand the nature of creativity, as well as how to measure and develop it. In this essay, I have tried to characterize work I have done in three stages to pursue this understanding. I started with the triarchic theory and its implications for creative intelligence. I moved, along with Todd Lubart, to the investment theory of creativity. And finally, I developed a theory of creative leadership, along with colleagues James Kaufman, Jean Pretz, and Christopher Rate. In a sense, this latest work is a culmination of everything that came before. Where will it lead? I have no idea. I'm just not creative enough to answer that question!

\section{References}

Amabile, T. M. (1983). The social psychology of creativity. New York: Springer.

Ayman, R. (2004). Situational and contingency approaches to leadership. In J. Antonakis, A. T. Cianciolo, \& R. J. Sternberg (Eds.), The nature of leadership (pp. 148-170). Thousand Oaks, CA: Sage Publications.

Camara, W. J., \& Schmidt, A. Z. (1999). Group differences in standardized testing and social stratification (College Board Report No. 99-5). New York: College Entrance Examination Board.

Cattell, R. B., \& Cattell, H. E. P. (1973). Measuring intelligence with the Culture Fair Tests. Champaign, IL: Institute for Personality and Ability Testing.

Frensch, P. A., \& Sternberg, R. J. (1989). Expertise and intelligent thinking: When is it worse to know better? In R. J. Sternberg (Ed.), Advances in the psychology of human intelligence (Vol. 5, pp. 157-188). Hillsdale, NJ: Lawrence Erlbaum Associates.

Garcia, J., \& Koelling, R. A. (1966). The relation of cue to consequence in avoidance learning. Psychonomic Science, 4, 123-124.

Gardner, H. (1991). The unschooled mind. New York: Basic Books.

Gardner, H. (1995). Leading minds. New York: Basic Books.

Gardner, H. (2004). Changing minds: The art and science of changing our own and other people's minds. Boston, MA: Harvard Business School Press.

Grigorenko, E. L., Jarvin, L., \& Sternberg, R. J. (2002). School-based tests of the triarchic theory of intelligence: Three settings, three samples, three syllabi. Contemporary Educational Psychology, 27, 167-208.

Henry, P. J., Sternberg, R. J., \& Grigorenko, E. L. (2004). Capturing successful intelligence through measures of analytic, creative, and practical skills. In O. Wilhelm \& R. W. Engle (Eds.), Handbook of understanding and measuring intelligence (pp. 295-311). Thousand Oaks, CA: Sage Publications.

Linacre, J. M. (1989). Many-facet Rasch measurement. Chicago, IL: MESA Press.

Linacre, J. M. (1998). Many-facet Rasch measurement. Retrieved July 6, 2006, from http://www.winsteps.com/facetman/index.htm.

Lubart, T. I. (1994). Creativity. In R. J. Sternberg (Ed.), Thinking and problem solving (pp. 290-332). San Diego: Academic Press.

Lubart, T. I., \& Sternberg, R. J. (1995). An investment approach to creativity: Theory and data. In S. M. Smith, T. B. Ward, \& R. A. Finke (Eds.), The creative cognition approach (pp. 269-302). Cambridge, MA: MIT Press.

McArdle, J. J. (1994). Structural factor analysis experiments with incomplete data. Multivariate Behavioral Research, 29, 409-454.

McArdle, J. J., \& Hamagami, F. (1992). Modeling incomplete longitudinal and cross-sectional data using latent growth structural models. Experimental Aging Research, 18, 145-166.

Rubenson, D. L., \& Runco, M. A. (1992). The psychoeconomic approach to creativity. New Ideas in Psychology, 10, 131-147.

Schank, R., \& Abelson, R. P. (1977). Scripts, plans, goals, and understanding: An inquiry into human knowledge structures. Hillsdale, $\mathrm{NJ}$ : Erlbaum.

Sloman, S. A. (1996). The empirical case for two systems of reasoning. Psychological Bulletin, 119, 3-22.

Sternberg, R. J. (1977). Intelligence, information processing, and analogical reasoning: The componential analysis of human abilities. Hillsdale, NJ: Lawrence Erlbaum Associates.

Sternberg, R. J. (1979). The nature of mental abilities. American Psychologist, 34, 214-230.

Sternberg, R. J. (1980). Sketch of a componential subtheory of human intelligence. Behavioral and Brain Sciences, 3, 573-584.

Sternberg, R. J. (1982). Natural, unnatural, and supernatural concepts. Cognitive Psychology, 14, 451-488.

Sternberg, R. J. (1984). Toward a triarchic theory of human intelligence. Behavioral and Brain Sciences, 7, 269-287.

Sternberg, R. J. (1985). Beyond IQ: A triarchic theory of human intelligence. New York: Cambridge University Press.

Sternberg, R. J. (1988). Mental self-government: A theory of intellectual styles and their development. Human Development, 31, 197-224.

Sternberg, R. J. (1993). Sternberg Triarchic Abilities Test. Unpublished test.

Sternberg, R. J. (1995a). In search of the human mind. Orlando, FL: Harcourt Brace College Publishers.

Sternberg, R. J. (1995b). Love as a story. Journal of Social and Personal Relationships, 12, 541-546.

Sternberg, R. J. (1997a). Successful intelligence. New York: Plume.

Sternberg, R. J. (1997b). Thinking styles. New York: Cambridge University Press.

Sternberg, R. J. (1998). Love is a story. New York: Oxford University Press.

Sternberg, R. J. (1999a). The theory of successful intelligence. Review of General Psychology, 3, 292-316.

Sternberg, R. J. (1999b). A propulsion model of types of creative contributions. Review of General Psychology, 3, 83-100.

Sternberg, R. J. (2003). A duplex theory of hate: Development and application to terrorism, massacres, and genocide. Review of General Psychology, 7, 299-328.

Sternberg, R. J., \& Clinkenbeard, P. R. (1995). The triarchic model applied to identifying, teaching, and assessing gifted children. Roeper Review, $17,255-260$.

Sternberg, R. J., Ferrari, M., Clinkenbeard, P. R., \& Grigorenko, E. L. (1996). Identification, instruction, and assessment of gifted children: A construct validation of a triarchic model. Gifted Child Quarterly, 40, $129-137$.

Sternberg, R. J., \& Gastel, J. (1989a). Coping with novelty in human intelligence: An empirical investigation. Intelligence, 13, 187-197.

Sternberg, R. J., \& Gastel, J. (1989b). If dancers ate their shoes: Inductive reasoning with factual and counterfactual premises. Memory and Cognition, 17, 1-10.

Sternberg, R. J., Grigorenko, E. L., Ferrari, M., \& Clinkenbeard, P. (1999). A triarchic analysis of an aptitude-treatment interaction. European Journal of Psychological Assessment, 15, 1-11.

Sternberg, R. J., Hojjat, M., \& Barnes, M. L. (2001). Empirical aspects of a theory of love as a story. European Journal of Personality, 15, 1-20.

Sternberg, R. J., Kaufman, J. C., \& Pretz, J. E. (2001). The propulsion model of creative contributions applied to the arts and letters. Journal of Creative Behavior, 35, 75-101.

Sternberg, R. J., Kaufman, J. C., \& Pretz, J. E. (2002). The creativity 
conundrum: A propulsion model of kinds of creative contributions. New York: Psychology Press.

Sternberg, R. J., Kaufman, J. C., \& Pretz, J. E. (2003). A propulsion model of creative leadership. Leadership Quarterly, 14, 455-473.

Sternberg, R. J., Kaufman, J. C., \& Pretz, J. E. (2004). A propulsion model of creative leadership. Creativity and innovation management, 13, 145153.

Sternberg, R. J., \& Lubart, T. I. (1991). An investment theory of creativity and its development. Human Development, 34, 1-31.

Sternberg, R. J., \& Lubart, T. I. (1995). Defying the crowd: Cultivating creativity in a culture of conformity. New York: Free Press.

Sternberg, R. J., \& Lubart, T. I. (1996). Investing in creativity. American Psychologist, 51, 677-688.

Sternberg, R. J., \& the Rainbow Project Collaborators (2005). Augmenting the SAT through assessments of analytical, practical, and creative skills. In W. Camara \& E. Kimmel (Eds.), Choosing students: Higher education admission tools for the 21st century (pp. 159-176). Mahwah, NJ: Lawrence Erlbaum Associates.

Sternberg, R. J., The Rainbow Project Collaborators, \& University of Michigan Business School Project Collaborators (2004). Theory-based university admissions testing for a new millennium. Educational Psychologist, 39, 185-198.

Sternberg, R. J., Torff, B., \& Grigorenko, E. L. (1998a). Teaching for successful intelligence raises school achievement. Phi Delta Kappan, 79, $667-669$.

Sternberg, R. J., Torff, B., \& Grigorenko, E. L. (1998b). Teaching triarchically improves school achievement. Journal of Educational Psychology, 90, 374-384.

Sternberg, R. J., \& Vroom, V. H. (2002). The person versus the situation in leadership. Leadership Quarterly, 13, 301-323.

Tetewsky, S. J., \& Sternberg, R. J. (1986). Conceptual and lexical determinants of nonentrenched thinking. Journal of Memory and Language, $25,202-225$.

Wothke, W. (2000). Longitudinal and multigroup modeling with missing data. In T. D. Little, K. U. Schnabel, \& J. Baumert (Eds.), Modeling longitudinal and multilevel data (pp. 219-240). Mahwah, NJ: Lawrence Erlbaum Associates.

Zhang, L-F., \& Sternberg, R. J. (2005). A threefold model of intellectual styles. Educational Psychology Review, 17, 1-53.

Zhang, L.-F., \& Sternberg, R. J. (2006). The nature of intellectual styles. Mahwah, NJ: Lawrence Erlbaum Associates, Publishers.

Received April 28, 2006

Revision received April 28, 2006

Accepted April 28, 2006 